\title{
Enterprise Architecture Framework with Early Business/ICT Alignment for Extended Enterprises
}

\author{
Llanos Cuenca, Andres Boza, and Angel Ortiz \\ Research Centre on Production Management and Engineering (CIGIP) \\ Universidad Politécnica de Valencia, Camino de Vera s/n, 46022 Valencia, Spain \\ \{llcuenca, aboza, aortiz\} @cigip.upv.es
}

\begin{abstract}
Incorporating information and communication technology (ICT) is strongly necessary in extended enterprises. To do this, enterprise engineering approach has important benefits; however, there is not a complete framework to model ICT components and ICT/business alignment. This paper presents an enterprise architecture framework for extended enterprises. The main aim enclosed in this paper is to provide a modeling framework from enterprise engineering approach which including ICT. A comparative analysis has been conducted in life cycle phases, modeling views and strategic alignment between different enterprise architectures. Next, the required building blocks have been proposed: ICT conceptualization, application portfolio, maturity model, alignment heuristics and strategic dependencies. This proposal has been applied in the collaborative order management process of a ceramic tile company.
\end{abstract}

Keywords: Enterprise Engineering, Business and ICT Strategic Alignment, Enterprise Architecture Framework.

\section{Introduction}

The current economic conditions and the high level of market uncertainty, forces the companies to be in a continuous adaptation to respond constant changes. The competitive advantages in the changing business environment have moved organizational structures from single enterprises to extended or virtual enterprise networks. The collaboration of enterprises requires that all of the enterprise elements should interact efficiently with each other based upon a complete framework [1]. Information technology allows making better the value chain (improving the enterprise processes and defining new processes) changing the way companies do business. In this sense, it is important to define a framework to model business and information and communication technology components, and its alignment, in an extended enterprise.

In this paper we propose a modeling framework from an enterprise engineering approach identifying views, life cycle and building blocks to model extended enterprises. This framework incorporates in early life cycle phases the required elements for business and information technology alignment. 


\section{Extended Enterprises and Enterprise Architecture}

Nowadays many industrial organizations are focusing specifically on linking and unifying supply chains. This linking process leads to the synchronized behavior of all participants [2]. They form entities, commonly called extended enterprises (EE). Extended Enterprise has been defined as: "Individual companies work together to form inter-enterprise networks across the product value chain in order to survive and achieve business success" [3]. The Extended Enterprise follows a philosophy where people throughout the business supply chain participate in the decision-making process [4].

In the modern global competitive environment, manufacturing enterprises need active co-operation with a large network of suppliers and customers to form extended enterprises [5]. With inter-organizational networks, firms begin to perceive the benefits derived from a vertical disintegration process which enables them to concentrate on their distinctive capacities, while identifying and developing mechanisms which boost the rapid configuration of operative structures that are quick to reconfigure and to adapt to rapidly changeable environments [6]. Creating new organizational forms requires the intense use of information and communication technology (ICT).

Enterprise architecture is a key issue in the development of enterprises supporting by technology. Enterprise architecture should have addressed more on how to align of business strategy to technology for implementation, and not just focused on business or IT with separated research and development [7].

\section{Enterprise Architectures and Modeling Frameworks Review}

Enterprise engineering (EE) concerns the analysis, optimization and re-engineering of all or part of business processes, information systems and organization structures in an enterprise or in an enterprise network [8].

According to Hoogervorst [9] this engineering approach has important benefits such as: 1) the formal approach for addressing organized complexity and the realization of a unified and integrated design, 2) the formal identification of all coordination actions makes clear responsibilities. These benefits generally do not appear with other types of business process modeling. To ensure that this design is carried out coherently the concept of enterprise architecture arises. Enterprise architecture (EA) is defined as a way to structure and design the company's organization and operations. Enterprise architecture is a coherent whole of principles, methods and models that are used in the design and realization of an enterprise's organizational structure, business processes, information systems, and infrastructure [10].

The framework, as it applies to the enterprise, is a logical structure for classifying and organizing the descriptive representations of an enterprise that are significant to the management of the enterprise as well as to the development of the enterprise systems [11]. An enterprise architecture framework is applied to describe both the current (as-is) and future (to-be) states [12]. The framework should also simplify the enterprise architecture development, since it helps to articulate how the different components of the architecture relate to one another. A framework should provide a general mechanism for defining views. Views are used in modeling because the 
complexity of an enterprise makes it unfeasible for a single descriptive representation to be comprehensible in its entirety [13].

Another adjacent concept to EA is Enterprise Modeling (EM). EM describes the EA from various viewpoints in detail to allow specifying and implementing the systems [7]. The use of these models in enterprise engineering can shorten design times and increase modeling consistency [14].

Enterprise models have a life cycle that is related to the life cycle of the modeled entity. EM uses modeling languages, methods and tools chosen according to the life cycle phase (or life cycle activity) of the enterprise. Several architecture frameworks exist today and they all have a modeling framework organizing enterprise model that may have to be created during the life of a business entity [15].

All the enterprise architectures contain views in their frameworks, however, life cycle, building blocks, and how the building blocks fit together, is not defined by all of them [16].

\subsection{Comparative Analysis between Enterprise Architecture Frameworks}

The Enterprise architectures analyzed have been: TOGAF [17], GERAM [18], IE-GIP [19], Zachman [20] and EAP [21]. The comparative analysis has been conducted in life cycle phases (Identification, Conceptualization, Requirements Definition, Design, Implementation Description, Construction, Operation and Decommission) and modeling views (Business view, Information view, Data view, Application view, Technological view, Organizational view and Resource view).

We can summarize that some modeling views are included with the same name in the enterprise architecture frameworks analyzed. In other cases, the modeling views are included but with a different name, finally other views are not explicitly included but can be complemented from other views. Similar conclusions were obtained from life cycle analysis.

The next figure shows the relationships between modeling views and life cycle phases. The identification and conceptualization phases, do not take into account the information, resources, data, applications and technology views.

The requirements definition phase incorporates the information, resources and data views. Only from design specification are considered the applications and technology views (To abbreviate the figure 1 does not include operation and decommission phases).

As discussed earlier, ICT is very important for the extended manufacturing and its alignment with business process and business strategies. The figure above shows that it is not possible to define aspects of information, resources, data, application and technology in early stages of life cycle. Incorporating information systems and information technology in the organizations have considerable risks, and these risks are increased when a strategic plan for its incorporation is not done.

There are a number of proposals that relate the alignment models with enterprise architectures [22] [23] [24] 25]. In most of cases, the strategic alignment is conducted from business strategy to organizational infrastructure. ICT strategy is hardly defined and when it is done, it does not influence in business strategy. So, it is necessary to improve the definition of ICT strategy and its alignment with business strategy in enterprise architecture. 


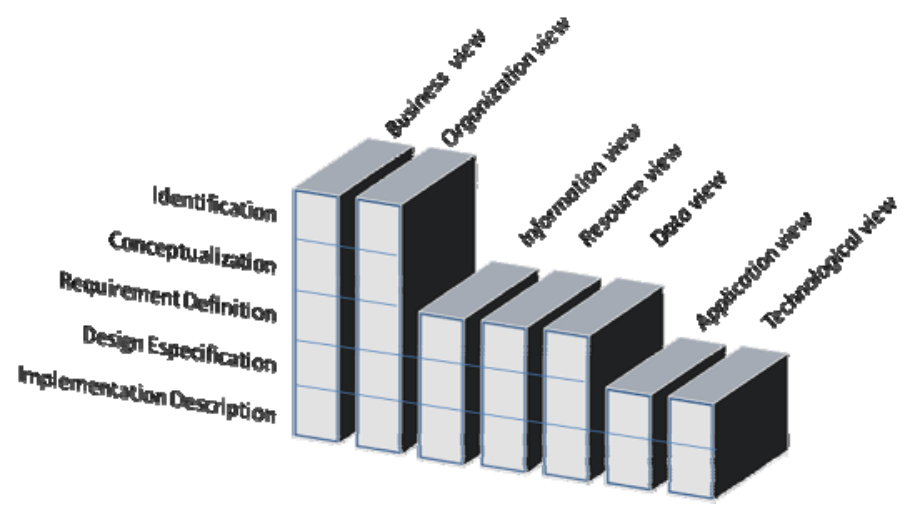

Fig. 1. The incorporation of modeling views in life cycle phases of enterprise architectures

According [26] in the enterprise architecture approach is not defined how to align and what to align. It is necessary identify what elements must be included in the enterprise architecture framework. The table 1 shows these elements and checks if they are included or not in the enterprise architectures framework analyzed. In some cases, this elements are mentioned in the enterprise architecture but it is not identified how to define them (this case has been labeled as "Limited" in the table).

Table 1. ICT and alignment components

\begin{tabular}{lccccc}
\hline & Togaf & Geram & IE-GIP & Zachman & EAP \\
\hline $\begin{array}{l}\text { ICT strategy } \\
\begin{array}{l}\text { Business and IT } \\
\text { alignment assessment }\end{array}\end{array}$ & Yes & No & No & Limited & Limited \\
$\begin{array}{l}\text { Incorporating IT } \\
\text { definition in earlier life } \\
\text { cycle phases }\end{array}$ & Limited & No & Limited & Limited & Limited \\
$\begin{array}{l}\text { Incorporating } \\
\text { application and services } \\
\text { portfolio }\end{array}$ & Limited & No & No & Limited & Limited \\
$\begin{array}{l}\text { Incorporating business } \\
\text { and IT alignment } \\
\text { maturity model }\end{array}$ & No & No & No & No & Limited \\
\hline
\end{tabular}

\section{Enterprise Architecture Framework for Extended Manufacturing}

The identified ICT and alignment components must be incorporated in the enterprise architecture framework in order to facilitate ICT strategic definition and alignment with business strategy in extended manufacturing. 
We propose new building blocks according to ICT strategy components: 1) ICT conceptualization, 2) application portfolio and 3) maturity model. Other building blocks are proposed in order to promote strategic alignment between business and ICT: 4) alignment heuristics and 5) strategic dependencies.

1) ICT Conceptualization: The purpose of this building block is that the company validates whether the ICT strategy is fully established for the company and business entity. ICT conceptualization is a checklist to indicate what documents have been completed. Finally, it must also carry out a joint analysis with the business strategy. The ICT objectives may precede the formulation of business objectives and will be used as input to their development.

2) Application portfolio: 2.1) As-Is portfolio: The purpose of the as-is portfolio is to support the information associated with each application and its relationships with as-is business objectives. 2.2) To-Be portfolio: The purpose of the to-be portfolio is to support the information associated with each application and its relationships with tobe business objectives. There must be at least a relationship with a business objective. 2.3) Application and services portfolio: The applications and services portfolio include those that have been identified in the to-be portfolio and those who remain in the as-is portfolio. Each one can be associated with business objectives and business process that execute them.

3) Maturity Model: It is based on the maturity models of [27] and [28] and allows you to define the maturity level of strategic alignment. The building block maturity model allows identifying the maturity level reached by the business entity. It is important to define the revision date and the last level assigned to analyze the alignment evolution.

4) Alignment heuristics: Alignment heuristics are used in this case to detect weakness in business and ICT alignment. By using this building block, different views are related by an alignment question. The company will react with improvement actions depending on the answer.

5) Strategic dependencies: The strategic dependencies model is based on $\mathrm{i} *$ framework [29]. The strategic dependency building block represents the resource, task or

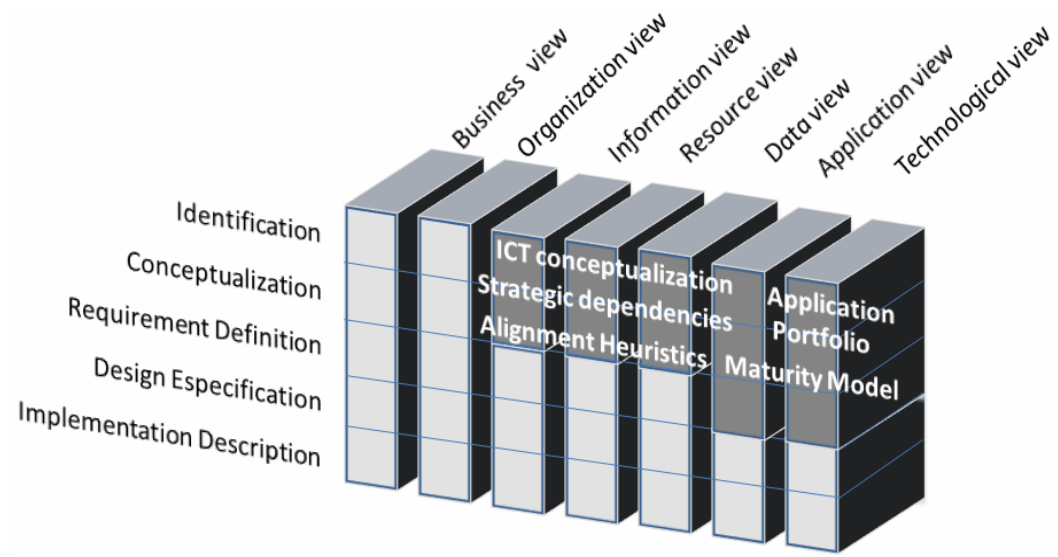

Fig. 2. Enterprise architecture framework for extended manufacturing 
goal dependencies among different actors (roles, organizational units, organization cells or set of roles). It also indicates whether or not dependency is critical for the business entity. The purpose is to detect dependencies between actors.

The figure 2 shows as the modeling views have been extended in the enterprise architecture framework proposed.

The relations between new elements described above, and its location in each view and modeling phase can be found in [16].

\section{Case Study}

This proposal has been applied in a ceramic tile company. It was necessary to identify the components of extended manufacturing process and several interviews with the managers appointed by the company. The business entity selected was the collaborative order management because is a critical process for the company. Information systems and information technology are essential to support this process.

The business and ICT conceptualization was carried out after identifying the business entity. With the definition of the alignment heuristic at this stage, was possible to identify aspects that had not been well resolved in the conceptualization.

The strategic dependencies model helped to identify the dependencies between actors, and allowed detecting bottlenecks and vulnerabilities. First, the actors involved were identified: suppliers, manufacturers, wholesalers and customers (bringing together retailers and end customers). Besides these actors, we propose a new one to be modeled, the computer system, which includes the information system and technology to use, in this way, strategic relationships with it can be modeled.

The application and services portfolio has enabled the company to link the enterprise business processes to applications and services at the macro level through goals. Also, it has allowed a prioritization of the applications.

The maturity model has allowed a detailed analysis of the alignment between business and ICT, with an allocation of values from one to five, where one represents the lowest value. For the company, the result was a low value which represents an emerging alignment. This encouraged the company to improve some alignment aspects.

The table 2 shows an example of strategic dependency identified in the company.

Table 2. Strategic dependency

\begin{tabular}{|l|}
\hline Type: \\
Name: Facilitating coordination and collaboration between wholesalers \\
Identification: SD-4 \\
Design responsible: U-13 \\
\hline Participants: Enterprise Integration Team \\
Depender actor: wholesalers \\
Dependee actor: ICT \\
Dependum: Objective, improving coordination and collaboration \\
Dependency type: critical \\
Chart: 1.1
\end{tabular}




\section{Conclusion}

This paper set out the needs for a modeling framework to include information and communication technology in early life cycle phases in extended enterprises. Traditionally, business strategy is the driver of organization and IT infrastructure. The alignment it is not concerned with the exploitation of emerging IT capabilities to impact new products and services; technology is not seen as competitive advantage. Hence it is necessary to extend all modeling views to all life cycle phases and to define the strategic alignment components.

The proposed framework allows defining ICT strategy, business and IT alignment assessment, incorporating IT definition in earlier life cycle phases, incorporating application and services portfolio and incorporates business and IT alignment maturity model by the following blocks: ICT conceptualization, application portfolio, maturity model, alignment heuristics and strategic dependencies.

Its application to an extended process, (collaborative order management), has allowed validating the usefulness of the framework.

\section{References}

1. Choi, Y., Kang, D., Chae, H., Kim, K.: An enterprise architecture framework for collaboration of virtual enterprise chains. Int. J. Adv. Manuf. Technol. 35, 1065-1078 (2008)

2. Vasiliu, L., Browne, J.: An integrated modeling approach of the Extended Enterprise using fractals, game theory and neural networks structure. In: The Proceedings of the 9th International Conference of Concurrent Enterprising, Espoo, Finland, June 16-18 (2003)

3. Zhang, J., Browne, J.: Extended and Virtual Enterprises - Similarities and Differences. International Journal of Management Systems (1999)

4. O'Neill, H., Sackett, P.: The Extended Manufacturing Enterprise Paradigm. Management Decision 32(8), 42-49 (1994)

5. Cheng, K., Popov, Y.: Internet-enabled modelling of extended manufacturing enterprises using process-based techniques. Int. J. Adv. Manuf. Technol. 23, 148-153 (2004)

6. Camarinha-Matos, L.M., Afsarmanesh, H.: Collaborative networks: a new scientific discipline. J. Intell. Manuf. 16(4), 439-452 (2005)

7. Chen, D., Doumeningts, G., Vernadat, F.: Architectures for enterprise integration and interoperability: past, present and future. Computers in Industry 59, 647-659 (2008)

8. Vernadat, F.: Enterprise Modeling and Integration. In: Principles and Applications. Chapman \& Hall, Boca Raton (1996)

9. Hoogervorst, J.: Enterprise Governance and Enterprise Engineering. Springer, Heidelberg (2009)

10. Lankhorst, M.M.: Enterprise Architecture Modeling - the Issue of Integration. Advanced Engineering Informatics. Engineering Computing and Technology 18(4), 205 (2004)

11. Inmon, W.H., Zachman, J.A., Geiger, G.J.: Data stores, data warehousing and the Zachman framework. McGraw-Hill, New York (1997)

12. Tang, A., Han, J., Chen, P.: A Comparative Analysis of Architecture Frameworks. Technical Report SUTIT-TR2004.01, Swinburne University of Technology (2004)

13. Martin, R., Robertson, E.: Architectural principles for enterprise frameworks (2004)

14. Chen, D., Vernadat, F.: Standard on enterprise integration and engineering-state of the art. Int. J. Computer Integrated Manufacturing 17(3), 235-253 (2004) 
15. Bernus, P., Nemes, L., Schmidt, G.: Handbook on enterprise architecture. Springer, Berlin (2003)

16. Cuenca L.1., Ortiz A., Boza A.: Business and IS/IT Strategic Alignment Framework. DoCEIS 2010, IFIP AICT, vol. 314, pp. 24-31 (2010)

17. TOGAF The Open Group Architecture Framework, http: / / www. opengroup.org/togaf

18. IFIP-IFAC Task Force: Generalized Enterprise Reference Architecture and Methodology, Version 1.6.2, Annex to ISO WD15704, IFIP-IFAC Task Force (1999)

19. Ortiz, A., Lario, F., Ros, L.: IE-GIP. A proposal for a Methodology to Develop Enterprise Integration Program. Computers in Industry 40, 155-171 (1999)

20. Sowa, J., Zachman, J.: Extending and formalizing the framework for information-systems architecture. IBM Systems Journal 31(3), 590 (1992)

21. Luftman, J.: Assessing business-it alignment maturity. Communications of the Association for Information Systems 4(14) (2000)

22. Spewak, S.: Enterprise Architecture Planning: Developing a Blueprint for Data, Applications, and Technology. Wiley, Chichester (1993)

23. Wegmann, A., Balabko, P., Le, L., Reveg, G., Rychkova, I.: A Method and Tool for Business-IT Alignment. In: Enterprise Architecture Proceedings of the CAISE. Porto Univ., Porto, Portugal (2005)

24. Pereira, C., Sousa, P.: Enterprise Architecture: Business and IT Alignment. In: ACM Symposium on Applied Computing (2005)

25. Plazaola, L., Flores, J., Silva, E., Vargas, N., Ekstedt, M.: An Approach to Associate Strategic Business-IT Alignment Assessment to Enterprise Architecture. In: Conference on Systems Engineering Research, Stevens Institute of Technology Campus, USA (2007)

26. Wang, X., Zhou, X., Jiang, L.: A method of business and IT alignment based on enterprise architecture (2008)

27. Chen, H.M.: SOA, Enterprise Architecture, and Business-IT Alignment: An Integrated Framework. In: Proceeedings of the 6th International Workshop on System/Software Architectures (2007)

28. Santana, R.G., Daneva, M., van Eck, P.A.T., Wieringa, R.J.: Towards a business-IT alignment maturity model for collaborative networked organizations. In: Proceedings of the International Workshop on Enterprise Interoperability Munich, Germany, pp. 70-81 (2008)

29. Yu, E.: Modeling Strategic Relationships for Process Reengineering. PhD thesis (1995) 